\title{
Study of iron deficiency anemia in non-pregnant young females at a tertiary care center
}

\author{
Goldee Khurana ${ }^{1 *}$, Joginder Singh ${ }^{2}$
}

1Senior Resident, Department of Medicine, Government Medical Collage, Kathua, Jammu \& Kashmir, INDIA. 2Assistant Professor, Department of Medicine, Government Medical Collage, Rajouri, Jammu \& Kashmir, INDIA. Email: goldeekhurana72@gmail.com

$\underline{\text { Abstract }}$

Background: Anemia remains a major challenge for the health and development of women and children in low and middleincome countries. Anemia is a serious public health problem affecting 293.1 million children and 468.4 million nonpregnant women in LMICs. Though many programmes are focussed on pregnant and lactating mothers, it is necessary to focus on nonpregnant, nonlactating females of reproductive age group. Present study is focussed on study of iron deficiency anemia in non-pregnant young females at a tertiary care center. Material and Methods: This was a cross-sectional, observational study conducted in female patients of reproductive age 19-42 years old with iron deficiency anaemia. Results: Total 513 patients satisfying inclusion and exclusion criteria were considered for present study. Patients from age group 19 to 26 years were $54 \%$, followed by 27 to 34 years age group (26\%) and 35-42 years age group (20\%). Literacy status was upto $12^{\text {th }}$ standard in $65 \%$, while $23 \%$ were illiterate and only $12 \%$ were graduation and above. Most patients were either housewife (56\%) or labourer/farmer (21\%). As per Socio-economic status class I, II, III, IV and V patients were 9\%, 17\%, $28 \% 21 \%$ and $25 \%$ respectively. $71 \%$ patients had normal BMI, $17 \%$ were underweight while $11 \%$ had BMI $>25$. Most patients had age of marriage as $21-30$ years $(72 \%)$, followed by less than 20 years $(24 \%)$ and more than 30 years $(4 \%)$. In patients with anemia $82 \%$ patients had their first pregnancy at 21-30 years age. Most patients had 0-2 number of pregnancies (78\%) and 0-2 number of live children (74\%). $55 \%$ patients were not using any contraceptive while $16 \%$ were using condoms and $14 \%$ underwent tubectomy. Conclusion: Anemia as a public health issue in developing country like India can not be eradicated without interventions right form childhood-to-adolescence to reproductive ages rather than targeted programmes at the time of pregnancy and lactation.

Key Words: anemia, iron deficiency anemia, young female

\section{*Address for Correspondence:}

Dr Goldee Khurana, Senior Resident, Department of Medicine, Government Medical Collage, Kathua, Jammu \& Kashmir, INDIA.

Email: goldeekhurana72@gmail.com

Received Date: 04/04/2020 Revised Date: 22/05/2020 Accepted Date: 10/06/2020

DOI: https://doi.org/10.26611/10211512

This work is licensed under a Creative Commons Attribution-NonCommercial 4.0 International License. (cc) $)$ EY-NC

\begin{tabular}{|l|l|}
\hline \multicolumn{2}{|c|}{ Access this article online } \\
\hline Quick Response Code: & Website: \\
& www.medpulse.in \\
\hline & \\
& \\
\hline
\end{tabular}

\section{INTRODUCTION}

Anemia remains a major challenge for the health and development of women and children in low and middleincome countries (LMICs). Anemia is a serious public health problem affecting 293.1 million children and 468.4 million nonpregnant women in LMICs. ${ }^{1,2}$ In most LMICs, anemia is a major cause of child and maternal mortality and is associated with an increased risk of low birth weight, cognitive impairment, increased susceptibility to infection, ${ }^{1}$ and delayed physical and mental development with diminished ability to work. ${ }^{1,3}$ Significantly, anemia serves as an indicator of socioeconomic disadvantage because it is inversely related to the socioeconomic status of households in developing settings ${ }^{1,4}$; individuals with low socioeconomic status are at a higher risk of exposure to anemia and its sequelae. ${ }^{3}$ To address the high anaemia burden, the World Health Assembly set a target of achieving a $50 \%$ reduction of anaemia in women of reproductive age by 2025 relative to 2010 levels, but no South Asian country is on track to meet this target. ${ }^{5}$ The contribution of iron deficiency in the aetiology of anaemia is major in countries where the prevalence of anaemia is 
more than 40 per cent, such as India and especially in rural populations. ${ }^{6}$ Iron deficiency usually develops in a sequential manner over a period of negative iron balance, such as periods of blood loss and/or prolonged irondeficient diet, accelerated growth in children and adolescents as well as during pregnancy and lactation. ${ }^{7}$ In addition, although iron deficiency anaemia accounts for most of the anaemia that occurs in underprivileged environments, several other possible causes should be noted. These include haemolysis occurring with malaria; glucose-6-phosphate dehydrogenase deficiency; congenital hereditary defects in haemoglobin synthesis; and deficits in other nutrients, e.g. vitamins A, B12,, and $\mathrm{C}$, and folic acid. Blood loss such as that associated with schistosomiasis, hookworm infestation, haemorrhage in childbirth, and trauma, can also result in both iron deficiency and anaemia. Lastly, as with vitamin A deficiency, inhibition of the normal metabolism of iron can result in anaemia. ${ }^{8}$ Though many programmes are focussed on pregnant and lactating mothers, it is necessary to focus on nonpregnant, nonlactating females of reproductive age group. Present study is focussed on study of iron deficiency anemia in non-pregnant young females at a tertiary care center.

\section{MATERIAL AND METHODS}

This was a cross-sectional, observational study conducted in Department of Medicine, Government Medical Collage, Kathua. Study duration was 3 months (September to November 2019). Institutional ethical committee approval was taken for present study.

Inclusion criteria -

females of reproductive age 19-42 years old with iron deficiency anaemia.

\section{RESULTS}

In present study, patients came to OPD for other complaints were included. Total 513 patients satisfying inclusion and exclusion criteria were considered for present study. Patients from age group 19 to 26 years were $54 \%$, followed by 27 to 34 years age group (26\%) and 35-42 years age group (20\%).

Table 1: Age distribution in anemia in patients:

\begin{tabular}{ccccc}
\hline Age in years & Mild & Moderate & Severe & Total \\
\hline $19-26$ & $162(32 \%)$ & $88(17 \%)$ & $26(5 \%)$ & $276(54 \%)$ \\
$27-34$ & $81(16 \%)$ & $41(8 \%)$ & $11(2 \%)$ & $133(26 \%)$ \\
$35-42$ & $71(14 \%)$ & $28(5 \%)$ & $5(1 \%)$ & $104(20 \%)$ \\
\hline \multicolumn{5}{c}{ Total } \\
\hline
\end{tabular}

Literacy status was upto $12^{\text {th }}$ standard in $65 \%$, while $23 \%$ were illiterate and only $12 \%$ were graduation and above. Most patients were either housewife (56\%) or labourer/farmer (21\%). As per Socio-economic status class I, II, III, IV and V patients were $9 \%, 17 \%, 28 \% 21 \%$ and $25 \%$ respectively. $71 \%$ patients had normal BMI, $17 \%$ were underweight while $11 \%$ had $\mathrm{BMI}>25$.

Table 2: Characteristics in anemia patients

\begin{tabular}{cccc}
\hline & Illiterate & 118 & $23 \%$ \\
Literacy status & Upto 12th std & 335 & $65 \%$ \\
& Graduation and above & 60 & $12 \%$ \\
Occupation & Housewife & 288 & $56 \%$ \\
\hline
\end{tabular}

\section{Exclusion criteria -}

- Female underwent abortion in last 6 weeks, Female with postpartum period less than 6 months, lactating mothers, females who had stopped breastfeeding less than 6 months before

- Female receiving iron tablets, received blood - Females having any chronic cardiovascular, gastrointestinal morbidity, diabetes, underwent any major surgery (in last 6 months), presently admitted for any reason

A written informed consent was taken for participation in present study. Reproductive age group women who were eligible and agree to participate have included in the study. From all the participants, hemoglobin concentration was measured using portable Sahli's Haemoglobinometer method and a peripheral blood smear was prepared. were included in present study.

A study proforma was prepared for present study.

Demographic data such as age, residence, obstetric history, proforma.

From all the participants, hemoglobin concentration was measured using portable Sahli's Haemoglobinometer method. Anaemia was defined as $<12$ gm/dl. Severe, $\mathrm{gm} / \mathrm{dl}, 7-9 \mathrm{gm} / \mathrm{dl}$ and 9-11.9 gm/ dl respectively. Data were entered in Microsoft excel and compiled. Statistical analysis was done using descriptive statistics.
- Pregnant females 


\begin{tabular}{cccc}
\hline & Government job & 16 & $3 \%$ \\
& Private job & 61 & $12 \%$ \\
& Self-employment & 38 & $7 \%$ \\
& Labourer/farmer & 110 & $21 \%$ \\
Socio-economic status* & I & 48 & $9 \%$ \\
& II & 86 & $17 \%$ \\
BII & 143 & $28 \%$ \\
Body mass index & IV & 106 & $21 \%$ \\
& V & 130 & $25 \%$ \\
& $18-25$ & 89 & $17 \%$ \\
& $>25$ & 366 & $71 \%$ \\
& 18 & 58 & $11 \%$ \\
\hline
\end{tabular}

Most patients had age of marriage as 21-30 years (72\%), followed by less than 20 years (24\%) and more than 30 years (4\%). In patients with anemia $82 \%$ patients had their first pregnancy at 21-30 years age. Most patients had 0-2 number of pregnancies (78\%) and 0-2 number of live children (74\%). $55 \%$ patients were not using any contraceptive while $16 \%$ were using condoms and $14 \%$ underwent tubectomy.

\begin{tabular}{cccc}
\multicolumn{4}{c}{ Table 3} \\
Characteristics & & No. of patients & Percentage \\
\hline Age of marriage (years) & $\leq 20$ & 125 & $24 \%$ \\
& $21-30$ & 367 & $72 \%$ \\
Age of first pregnancy (years) & $>30$ & 21 & $4 \%$ \\
& $\leq 20$ & 61 & $12 \%$ \\
Number of pregnancies & $21-30$ & 421 & $82 \%$ \\
& $>30$ & 31 & $6 \%$ \\
Number of live children & $0-2$ & 400 & $78 \%$ \\
& $3-4$ & 81 & $16 \%$ \\
Current contraception status & $>4$ & 32 & $6 \%$ \\
& $0-2$ & 380 & $74 \%$ \\
& $>2$ & 133 & $26 \%$ \\
& None & 281 & $55 \%$ \\
& Condom & 81 & $16 \%$ \\
& Oral Contraceptive Pills & 32 & $6 \%$ \\
& Intra Uterine Devices & 48 & $9 \%$ \\
& Tubectomy & 71 & $14 \%$ \\
\hline
\end{tabular}

\section{DISCUSSION}

The economic and social consequences of anaemia, as yet un-quantified, are thought to be enormous including a significant drain on health care, education resources and labour productivity, and reduced physical and mental capacity of large segments of the population. Iron deficiency is the leading cause of anemia, with women of reproductive age being particularly vulnerable to acquiring iron deficiency anemia (IDA) because of the increase in blood volume and muscle mass that occurs around puberty followed by regular menstruation, which increases the body's demand for iron. ${ }^{9}$ Infectious diseases such as malaria, tuberculosis, fevers, diarrhoea, parasitic infestations and other infections common in developing countries also contribute to anaemia9. The inflammation caused due to infections leads to poor nutrient absorption and increased nutrient losses. ${ }^{10}$ According to data from the second and third rounds of India's National Family Health Survey (NFHS) in 1997 and 2006, ${ }^{11,12}$ anaemia prevalence increased from $74 \%$ to $79 \%$ in children aged 6 to 36 months and from $52 \%$ to $56 \%$ in women aged 15 to 49 years. The lack of anaemia reduction is surprising given India's rapid economic growth9 during the same period, as anaemia rates are expected to decline approximately a quarter as fast as income increases. ${ }^{13}$ According to the National Family Health Survey (NFHS)-4, 53 per cent of non-pregnant women, 50.3 per cent of pregnant women (in the age group of 15-49 yr) and 58.5 per cent of children in the age group of 6-59 months had anaemia. ${ }^{14}$

In NFHS $4{ }^{14}$ major findings were

- The prevalence of anaemia decreases with schooling, from 56 percent among women with no schooling to 49 percent among women with 12 or more years of schooling. Across the same schooling groups, the prevalence of anaemia among men decreases from 29 percent to 18 percent.

- The proportion of anaemic women and men declines steadily as the wealth of the household increases (from $59 \%$ in the lowest wealth quintile 
to $48 \%$ in the highest wealth quintile among women and from $32 \%$ in the lowest wealth quintile to $17 \%$ in the highest wealth quintile among men).

- Women in urban areas are slightly less likely to be anaemic $(51 \%)$ than those in rural areas $(54 \%)$. The difference is larger for the prevalence of anaemia in men (25\% in rural areas versus $19 \%$ in urban areas).

WHO study noted that, the prevalence rates for reproductive age group pregnant women and non-pregnant women are $29 \%$ and $38 \%$, respectively; however, among different age group people, reproductive age group women were commonly affected which is nearly 468 million. ${ }^{15}$ In present study patients from age group 19 to 26 years were $54 \%$, followed by 27 to 34 years age group ( $26 \%$ ) and $35-$ 42 years age group (20\%). However, a recent subnational surveys have shown that between $50 \%$ and $90 \%$ of adolescents are anaemic during this critical period when lifelong habits are being formed. ${ }^{16}$ Literacy status was upto $12^{\text {th }}$ standard in $65 \%$, while $23 \%$ were illiterate and only $12 \%$ were graduation and above. In present study $77 \%$ patients were literate, which was similar to the studies conducted in Tamil Nadu (72\%) and Haryana (75\%). ${ }^{17,18}$ Whereas the study conducted in Orissa ${ }^{19}$ reported low literacy rate $(31.3 \%)$. This shows that literacy rate is high in the study area compared to that of census. The mean age of the participants was $28.4 \pm 7.8$ years which was similar to the study conducted in Haryana and Orissa. ${ }^{20}$ Most Indian girls reach menarche (thus start to experience significant iron losses) between age 12 and 14 years $^{21}$ and have their first child by age 19 years, ${ }^{14}$ it is important to intervene early. As per Socio-economic status class I, II, III, IV and V patients were $9 \%, 17 \%, 28 \% 21 \%$ and $25 \%$ respectively. Similar finding was reported by Bharati $\mathrm{P}$ et al.., ${ }^{17}$ and Panigrahi A et al. ${ }^{19}$. This could be due to the fact that those from lower economic status lack the ability to purchase the quality and/or quantity of foods compared with those from higher economic status. In the current study, significant association was also found between socio-demographic variables and anaemic status of the reproductive age group women in terms of religion, literacy status, occupation and socio-economic status. Similar findings were reported in other studies also. ${ }^{17,18,19,22} 55 \%$ patients were not using any contraceptive while $16 \%$ were using condoms and $14 \%$ underwent tubectomy. Regarding contraception usage among reproductive age group women, Sadeghian M et $a l .{ }^{23}$ also notes that the highest prevalence was found among those who did not use any method of contraception. This shows besides socio-economic factors, there are other factors like increased parity, reduced birth spacing and low usage of contraceptive methods may also indirectly influence the prevalence of anemia. In present study, $71 \%$ patients had normal BMI, $17 \%$ were underweight while $11 \%$ had BMI $>25$. Both low BMI (undernourished) and high BMI (overweight and obesity) are considered as risk factors for iron deficiency, 46 one known cause of anaemia. ${ }^{24}$ Although the population prevalence of low BMI in non-pregnant women decreased considerably, there was not a substantial decrease in anaemia. This suggests that women gained weight but did not necessarily experience improvements in micronutrient status or other factors underlying anaemia. The recommended iron intake in non-pregnant women is $12-18 \mathrm{mg}$ /day however over $90 \%$ women in India have a dietary intake below this recommendation at an average of only $9 \mathrm{mg} /$ day. ${ }^{25}$ The recommended iron intake is further increased in pregnancy to around $35 \mathrm{mg} /$ day. ${ }^{26}$ Therefore, dietary iron alone is not sufficient for iron requirements in non-pregnant women with iron deficiency or in pregnant women, to maintain hemoglobin levels. ${ }^{26} \mathrm{~A}$ major reason for poor compliance for IFA tablets is adverse effects such as gastric irritation, nausea, epigastric discomfort, and constipation. The adverse effects increase with the administration of higher doses of iron. ${ }^{27}$ Knowing the importance of consequences of anaemia, in 2012 World Health Assembly made a resolution and endorsed a "Comprehensive implementation plan on maternal, infant and young child nutrition". This plan has six global nutrition targets to be achieved in 2025 and second target specifically emphasising on $50 \%$ reduction of anaemia in reproductive age group women. ${ }^{28}$ IFA supplementation alongside behaviour change communication to improve pill-taking compliance, deworming, education on appropriate dietary choices and child feeding practices, promotion of delayed cord clamping, mandatory provision of fortified foods in public health programmes, and screening and treatment of non-nutritional causes of anaemia with a focus on malaria are simultaneously required to reduce anemia.

\section{CONCLUSION}

Despite progress in the last decade for anaemia reduction in children and pregnant women, anaemia continues to be a major public health concern in India. Anemia as a public health issue in developing country like India can not be eradicated without interventions right form childhood-toadolescence to reproductive ages rather than targeted programmes at the time of pregnancy and lactation. Further research is recommended to identify the specific risk factors for anaemia. It may be helpful to implement measures to improve nutritional knowledge and awareness among mothers and health workers. 


\section{REFERENCES}

1. Marn H, Critchley JA. Accuracy of the WHO Haemoglobin Colour Scale for the diagnosis of anaemia in primary health care settings in low-income countries: a systematic review and meta-analysis. Lancet Glob Health. 2016;4 (4):e251-e265.

2. Kassebaum NJ, Jasrasaria R, Naghavi M, et al.. A systematic analysis of global anemia burden from 1990 to 2010. Blood. 2014;123(5):615-624.

3. Balarajan Y, Ramakrishnan U, Ozaltin E, Shankar AH, Subramanian SV. Anaemia in low-income and middle income countries. Lancet. 2011;378(9809):2123-2135.

4. World Health Organization.Worldwide Prevalence of Anemia 1993-2005: WHO Global Database on Anemia. Geneva, Switzerland:World Health Organization; 2008.

5. WHO. Global nutrition targets 2025: anaemia policy brief (WHO/ NMH/NHD/14.4). Geneva: World Health Organization, 2014.

6. Petry N, Olofin I, Hurrell R, Boy E, Wirth J, Moursi M, et al.. The proportion of anemia associated with iron deficiency in low, medium, and high human development index countries: A systematic analysis of national surveys. Nutrients 2016; 8. pii: E693.

7. Acharya A Acharya A Meena RR. Retrospective study on prevalence of anaemia among pregnant women at booking in a health care centre in Udairamsar, Bikaner, Rajasthan, India. International Journal of Community Medicine and Public Health. January 2017 Vol 4 Issue 1, Page no. 235237

8. Iron Deficiency Anaemia Assessment, Prevention, and Control, A guide for programme managers, World Health Organisation , 2001

9. Kalaivani K. Prevalence and consequences of anemia in pregnancy. Indian J Med Res 2009;130:627-33.

10. Balarajan Y, Ramakrishnan U, Özaltin E, Shankar AH, Subramanian SV. Anaemia in low-income and middleincome countries. Lancet 2011; $378: 2123-35$.

11. Macro. National Family Health Survey (NFHS-2. India. Mumbai: IIPS, 2000: 1998-9.

12. IPPS. International Institute for Population Sciences and Macro International. National Family Health Survey (NFHS-3). India. Mumbai: IIPS, 2007: 2005-6.

13. The World Bank. World Bank national accounts data, and OECD National Accounts data files. GDP growth (annual $\%), 2018$

14. International Institute for Population Sciences. National Family Health Survey (NFHS-4). Mumbai: IIPS; 2016.

15. De Benoist B, McLean E, Egli, Cogswell M, eds. Worldwide prevalence of anaemia 1993-2005: WHO global database on anaemia. Geneva: World Health Organization; 2008
16. Santhya KG, Acharya R, Pandey N. Understanding the lives of adolescents and young adults (UDAYA) in Uttar Pradesh, India. New Delhi: Population Council, 2017.

17. Bharati P, Som S, Chakrabarty S, Bharati S, Pal M. Prevalence of anemia and its determinants among nonpregnant and pregnant women in India. Asia Pacific J Public Health. 2008;20(4):347-59.

18. Mangla M, Singla D. Prevalence of anaemia among pregnant women in rural [13] India: a longitudinal observational study. IJRCOG. 2016;5(10):3500-05

19. Panigrahi A, Sahoo PB. Nutritional anemia and its epidemiological correlates [14] among women of reproductive age in an urban slum of Bhubaneswar, Orissa. IJPH, 2011;55(4):317-20.

20. Verma R, Kharb M, Deswal S, Arora V, Kamboj R. Prevalence of anaemia among [15] women of reproductive age group in a rural block of northern India. Indian $\mathrm{J}$ Comm Health. 2014;26(Suppl S2):359-364.

21. Pathak PK, Tripathi N, Subramanian SV. Secular trends in menarcheal age in India - evidence from the Indian human development survey. PLoS One 2014;9:e111027.

22. Kamruzzaman, Rabbani G, Saw A, Sayem A, Hossain G. Differentials in the prevalence of anemia among nonpregnant, ever-married women in Bangladesh: multilevel logistic regression analysis of data from the 2011 Bangladesh Demographic and Health Survey. BMC Women's Health. 2015;15:54.

23. Sadeghian M, Fatourechi A, Lesanpezeshki M, Ahmadnezhad E. Prevalence of anemia and correlated factors in the reproductive age women in rural areas of Tabas. J fam Rep H. 2013;7(3):139-44.

24. Zhao L, Zhang X, Shen $\mathrm{Y}$, et al.. Obesity and iron deficiency: a quantitative meta-analysis. Obes Rev 2015;16:1081-93.

25. EFSA Panel on Food Additives and Nutrient Sources added to Food (ANS). "Scientific Opinion on the safety of heme iron (blood peptonates) for the proposed uses as a source of iron added for nutritional purposes to foods for the general population, including food supplements." EFSA Journal, Vol. 8, No. 4, 2010, p. 1585.

26. Krishnaswamy, K., et al. "Dietary guidelines for Indians: A manual." Hyderabad: National Institute of Nutrition, Indian Council of Medical Research, 2011.

27. Smith GA, Fisher SA, Doree C, Di Angelantonio E, Roberts DJ. Oral or parenteral iron supplementation to reduce deferral, iron deficiency and/or anaemia in blood donors. Cochrane Database Syst Rev 2014; 7 : CD009532.

28. Resolution WHA65.6. Comprehensive implementation plan on maternal, infant and young child nutrition. In: Sixty-fifth World Health Assembly Geneva, 21-26 May 2012. Resolutions and decisions, annexes. Geneva:World Health Organization; 2012:12- 13.

\section{Source of Support: None Declared Conflict of Interest: None Declared}

\section{Policy for Articles with Open Access:}

Authors who publish with MedPulse International Journal of Medicine, Print ISSN: 2550-7583, Online ISSN: 2636-4751 agree to the following terms: Authors retain copyright and grant the journal right of first publication with the work simultaneously licensed under a Creative Commons Attribution License that allows others to share the work with an acknowledgement of the work's authorship and initial publication in this journal.

Authors are permitted and encouraged to post links to their work online (e.g., in institutional repositories or on their website) prior to and during the submission process, as it can lead to productive exchanges, as well as earlier and greater citation of published work. 